\title{
Effects of Donor- and Supporter-Based Campaign Networks on Crowdfunding Campaign Success
}

\author{
Bin Wang \\ University of Texas \\ Rio Grande Valley \\ bin.wang@utrgv.edu
}

\author{
Babajide Osatuyi \\ University of Texas \\ Rio Grande Valley \\ babajide.osatuyi@utrgv.edu
}

\author{
Wanrong Hou \\ University of Texas \\ Rio Grande Valley \\ wanrong.hou@utrgv.edu
}

\begin{abstract}
Driven by the increasing popularity of crowdfunding, academic researchers have examined the impacts of internal social capital accumulated on crowdfunding platforms and external social capital formed through online and offline friend networks on campaign success. However, no research has examined the impacts of social networks from a structural perspective. In the current research, we investigate the extent to which donor-and supporter-based campaign network centralities affect the amount of capital a fundraising campaign is able to generate. Using a panel data set collected from a donation-based crowdfunding platform, Fundly, we reveal that campaign network centralities based on strong ties (shared donors) and weak ties (shared supporters) are more important predictors of fundraising success than the number of donors a campaign has.
\end{abstract}

\section{Introduction}

Crowdfunding refers to "a new [I]nternet-based method of fundraising in which individuals solicit contributions for projects on specialized crowdfunding websites" [1, p. 71]. Within a short five-year period, the global crowdfunding marketplace grew from $\$ 880$ million in 2010 to over $\$ 34$ billion in 2015 [2], and is expected to grow around $27 \%$ annually over the next few years [3]. Despite the opportunities associated the growth of the crowdfunding industry, the large number of players in this sector also presents crowdfunding platforms with intense competition. As the crowdfunding industry matures, consolidation is likely to occur where websites that fail to achieve a critical mass of users are eliminated from the marketplace.

Driven by the increasing popularity of crowdfunding and the challenges crowdfunding service providers face, academic researchers have examined factors that affect campaign success at both the lender and the campaign levels [e.g., 4, 5]. Among these studies, several have revealed the importance of social capital accrued internally on the crowdfunding platform and externally through the borrower's and lender's friend networks on lending behavior and campaign success [e.g., 6, 7-9]. Despite these early insights on the significance of social capital, the foci are primarily on the number of friends or connections a borrower or lender has. To the best of our knowledge, there has been no research examining the effects of campaign networks resulting from social capital. In the current research, we employ a unique approach by using social network analysis (SNA) [10] to analyze campaign networks formed as a result of social capital. Based on a panel data set collected from Fundly, a donation-based crowdfunding platform, we examine how the structure of campaign networks formed based on ties of different strengths - strong ties as a result of shared donors versus weak ties as a result of shared supporters - affect the amount of donation a campaign receives in the next period. This approach allows us to reveal hidden patterns on crowdfunding platforms beyond simple observables such as campaign characteristics, number of social media shares, number of donors, and amount received to date. Indeed, our results show that campaign network centralities based on strong ties (shared donors) and weak ties (shared supporters) are both important in predicting campaign success. Our research reveals the importance of social network structures and provides important strategic considerations for crowdfunding service providers.

\section{Literature Review}

\subsection{Crowdfunding}

Researchers have identified four main types of crowdfunding business models including rewards-, donation-, debt-based, and equity crowdfunding [11]. On rewards-based crowdfunding websites such as Kickstarter, individuals fund a project in exchange of a product or service delivered at a future time. The 
donation-based model used on websites such as GoFundMe allows charitable giving to funding campaigns. The debt-based model implemented by websites such as Kiva.org is also called microfinancing or person-to-person (P2P) lending and allows individuals to lend to borrowers and receive repayments on their contributions. On equity crowdfunding platforms such as AngelList, verified investors can invest in shares of a startup or small business and expect returns from their investments.

Multiple studies on crowdfunding have focused on the effects of social capital on funding success. For example, research on the borrowers' and lenders' online and offline friend networks $[6,9,12]$ reveals the significance of such external social capital on the borrowers' fundraising success. Similarly, internal social capital formed within the crowdfunding platform such as the number of projects a borrower has backed on the website [7] and group leader actions [8] also contributes positively to the success of a crowdfunding campaign. Despite the growing number of studies on crowdfunding and evidence showing the importance of social capital, no study has examined the performance of crowdfunding campaigns from the structural perspective using SNA. Our research on Fundly, a donation-based crowdfunding platform, allows us to examine the impacts of social networks in an underinvestigated crowdfunding business model. Examining the structural dimension of social network can help improve our understandings of the effects of different types of social networks. Moreover, investigating this relationship on a donation-based crowdfunding platform can inform scholars and practitioners about new insights which could increase the likelihood of crowdfunding success in this model. Next, we introduce the related literature on SNA that can inform us on crowdfunding campaign success.

\subsection{Social Network Theory}

Social network theory (SNT) examines social relationships using nodes that represent individual entities and ties that represent the connections between the entities [13]. In essence, a social network is a map of ties between nodes under investigation. Ties between the same set of nodes can vary and consequently create different networks. For instance, faculty members (nodes) in the same department can share a number of unique relationships or connections (ties) such as co-authoring on research articles, serving on the same committees, and volunteering at the same charity organization. Networks are often depicted using a social network graph with interconnection of points where the points represent the nodes and the lines connecting the points represent the ties. SNT presents the view that relationships between entities are important in understanding outcomes of their interaction rather than focusing on individual attributes of the entities as done in behavioral studies [13]. This view has been useful in explaining a wide range of phenomena across different contexts (e.g., computer networks [14], individuals [15, 16], organizational structure [17, 18], technology adoption [19], distance learning [20], and political endorsements [21]).

SNT stipulates that connections between nodes in a network can exist in two primary forms: as a strong tie or as a weak tie. The distinguishing factor between both ties is the notion of tie strength, which is defined as " a combination of the amount of time, the emotional intensity, the intimacy, and the reciprocal services that characterize the tie" [13, p. 1361]. Two nodes are said to share a strong tie if they have high tie strength connections that helps them form trusting relationships needed for successful collaboration. Weak ties on the other hand refer to links of lower tie strength and allows the use of bridges to connect otherwise isolated components. For example, in social networks, friends are strong ties, whereas acquaintances are weak ties. While recognizing the importance of strong ties, SNT also highlights the significance of weak ties in facilitating the flow of resources such as information among the components of a network [13, 22]. The reason is because a component with strong ties represent a tightly-knitted group and such nodes mostly have access to the same information. On the other hand, weak ties represent nodes that are further away or more dissimilar and hence introduce new information coming from other components in the network. Previous research has shown the importance of ties in organizational and online settings. For example, strong ties have been found to facilitate organizational knowledge transfer [23], booster organizational influence [24], and reduce conflict [25], but strong ties may also inhibit creativity [26]. On the other hand, weak ties contribute to a better chance of finding employment [27], foster creativity [26], and promote information diffusion in social networks [28, 29]. In crowdfunding, Liu et al. [9] revealed that, compared to a borrower's offline weak-tie friends, her offline strong-ties friends are more likely to lend to her.

The analysis of ties and their structure in a social network is referred to as SNA. SNA presents a number of structural mechanisms referred to as centrality measures that are useful for understanding network structures and the importance of a node in a network [30, 31]. In this study we examine two widely used centralities: degree centrality and eigenvector centrality. Degree centrality refers to the number of immediate connections of a node. Degree centrality is 
important because it represents a node's access to resources such as information and social capital. In the crowdfunding context, degree centrality indicates the number of other projects connected to a particular project through shared donors, supporters, or fundraisers. This means, a node (or campaign) is highly central when people associated with the campaign (e.g., donors, supporters, and fundraisers) are also associated with several other campaigns. Eigenvector centrality considers not only the immediate connections of a node but also the importance of these nodes connected to the focal node. That is, being connected to more influential nodes contributes to a higher eigenvector centrality of the focal node. In the crowdfunding context, the eigenvector centrality of a node (i.e., a campaign) is high if it is connected to other high value campaigns (i.e., campaigns with high degree centrality). As a result, two campaigns can have the same degree centrality (i.e., the same number of immediate connections), but the one that is connected to other more well-connected (i.e., influential) nodes will have a higher eigenvector centrality. Hence, degree centrality describes the "local" prominence of a node in a network, while eigenvector centrality characterizes the "global" prominence of a node in the network. Studies have linked performance outcomes to degree and eigenvector centralities of actors in a network. For example, degree centrality is an important predictor of individual performance in virtual R\&D teams [32] and contributes to the diffusion of Youtube videos [33]. The eigenvector centrality improve group performance and leader reputation [34], increase scholar productivity [35], and boost salesperson performance [36]. In the context of our study, degree and eigenvector centralities allow us better examine how the "status" or prominence of a node in the network can influence the success of campaigns.

\section{Research Context and Hypotheses}

\subsection{Crowdfunding on Fundly}

The current research focuses on donation-based crowdfunding platform Fundly (http://www.fundly. com) launched in 2009. Fundly allows individuals and organizations to pitch their fundraising initiatives and solicit donations from online users for a wide range of causes such as charity, school and education expenses, medical needs, family or sports events, and political campaigns. To start, the campaign initiator creates a fundraising campaign by setting its monetary goal and duration in days. Fundly also allows the campaign initiator to post pictures, videos, and provide brief and detailed descriptions of the campaign. Unlike many other crowdfunding platforms, Fundly does not impose any length restriction on the duration of the campaign and allows the campaign initiator to keep the donations received even if the campaign is not fully funded by the time it ends. On each campaign page, Fundly lists the number of donors to date, amount raised, days left in the campaign, and uses a horizontal bar to show the percentage of the goal that has been raised.

A member of the Fundly community can support a fundraising campaign in three different ways. First, the user can become a donor of the campaign by directly providing financial support. Each campaign page lists in detail the donors and the amount of each donation. Becoming a donor represents strong support of the cause as it involves financial contribution from the donor without expectation for any return. Second, a member can become a supporter of a campaign if she identifies with the cause but does not want to provide financial or fundraising support by clicking on "Supporter this Campaign" link. Users then have the options to post a comment on the campaign page to express their support and share the campaign on Facebook or through Twitter or email. Because a supporter does not involve any financial contribution, it represents a weak tie between the campaign and a user. Third, a community member can become a voluntary fundraiser for the campaign by creating a separate fundraising page on Fundly aimed at raising a portion of the overall campaign goal. All fundraisers for a campaign are listed on the campaign page, as well as the goal of and amount raised by each fundraiser. Fundraisers do not receive any financial incentive from Fundly. Thus, becoming a voluntary fundraiser signals the strongest support for a campaign.

When listing the donors and supporters of a campaign, Fundly provides a hyperlink to the member's profile based on a unique member ID, thus allowing us to uniquely identify each member. On the member profile page, Fundly further lists all campaigns that a member has fundraised for, donated to, or supported. Such member action data based on user IDs enables us to identify project-member relational data. Community members are able to click on each donor or supporter's profile link on a campaign page and browse other campaigns that the member has donated to or supported. Then, members can follow these links to the other campaigns, which creates a possible path of directing users from one campaign to another. When a campaign is connected to many other campaigns through shared donors or supporters, it has many paths that may funnel in visitors to or out of the campaign page. Next, we discuss how we construct project social networks based on the three different relationships discussed above. 


\subsection{Social Networks on Fundly}

Rather than constructing a network of actors, we construct a network of projects that are connected by the different types of actors (donors, supporters, fundraisers) on Fundly, similar to candidate-bycandidate and endorser-by-endorser networks used to investigate political campaign dynamics [21].

First, we can construct a donor-based project network by creating a connection (tie) between two campaigns (nodes) that share the same donor. Because donating to a campaign represents strong support, the connections between campaigns due to shared donors represent a strong tie. According to SNT, strong ties are associated a higher similarity between the nodes than weak ties [36]. Since previous research suggests that individuals donate to borrowers that are similar to themselves in terms of culture, social characteristics, or geography [37-40], a strong tie between two campaigns due to shared donors may represent a high homophily or affinity [33] due to similarities between the campaigns. When a campaign has a high degree or eigenvector centrality, it is connected to many other campaigns through shared donors. In addition, these connected campaigns may be similar to the focal campaign and may compete for the limited resources the donors have. As a result, the likelihood of the success for each campaign would be lowered due to the fact that increased competition reduces crowdfunding campaign success $[41,42]$. As a result, we expect that more strong ties in the donor-based campaign networks would negatively influence campaign success.

H1a: There is a negative association between the degree centrality of a campaign in the donor-based campaign network and campaign success.

H1b: There is a negative association between the eigenvector centrality of a campaign in the donorbased campaign network and campaign success.

Second, we can construct campaign networks based on shared supporters. When two campaigns share the same supporter, the two campaigns share a weak tie that is not as strong as the donation-based relationship. According to the SNT, weak ties serve as bridges to information or resources coming from other components of the network. When campaigns are connected to each other through shared supporters, users may go from one campaign to another, which leads to the flow of resources within the network. Social network research has suggested that weak ties are stronger than strong ties in accelerating information flow among components of a network [43]. Weak ties are more likely to bring heterogeneous information to the network than strong ties, due to the complexity of the nodes of weak ties. Therefore, more weak ties in the supporter-based campaign network allows a campaign to be exposed to new information or community members, leading to increased exposure and more future donation.

H2a: There is a positive association between the degree centrality of a campaign in the supporter-based campaign network and campaign success.

$\mathrm{H} 2 \mathrm{~b}$ : There is a positive association between the eigenvector centrality of a campaign in the supporterbased campaign network and campaign success.

Third, we can construct campaign networks based on fundraising relationships. Because these relationships represent the strongest among the three, campaign networks established based on fundraising relationships represent strong ties as well.

\section{Data and Methods}

\subsection{Data}

We collected monthly fundraising data on Fundly campaigns in the school and education category from February 2016 to June 2016 using an automated software agent. For each point of data collection, we constructed the fundraiser-, donor-, and supporterbased campaign networks and estimated network metrics using UCINET 6 [44]. Figure 1 illustrates the supporter, donor-, and fundraiser-based campaign networks in June 2016. As the figure shows, the supporter-based campaign network has one giant component on the bottom right and other more sparsely connected small components mimicking the shape of a crescent. The donor-based campaign network is sparser with more components, and the fundraiser-based campaign network is the sparsest with very few ties. Our subsequent data analyses focus on the donor- and supporter-based campaign networks due to the lack of fundraising activities on Fundly.

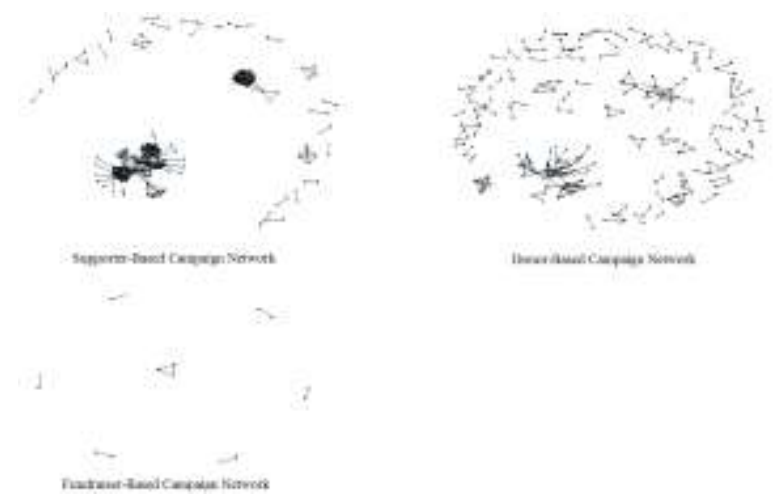

Figure 1. Campaign networks based on supporter, donor, and fundraiser relationships

Because Fundly lists all campaigns irrespective of their ending dates, we eliminated campaigns that were no longer active (i.e., days remaining was zero) from further econometric analyses on factors that influence 
campaign success. Overall, our sample consists of longitudinal data on 2,509 campaigns. Table 1 summarizes our sample campaign characteristics and Table 2 summarizes the numbers and percentages of campaign pairs that shared a specific number of donors or supporters. As shown in Table 1, the degree and eigenvector centralities of the campaigns based on shared donors or supporters are distinct from each other. As shown in Table 2, there are more campaign pairs that shared supporters than donors. The percentages of campaigns with shared donors or supporters are low for two reasons. First, a majority of the campaigns in our sample did not receive any donation or support within our sample period. As a result, they do not share donors or supporters with any other campaign. Second, for campaigns with donors or supporters, the campaigns do not share any donor or supporter with other campaigns, if these individuals do not donate to or support other campaigns.

Table 1. Campaign characteristics

\begin{tabular}{|l|c|c|c|r|}
\hline \multicolumn{1}{|c|}{ Variable } & Mean & $\begin{array}{c}\text { Std. } \\
\text { Dev. }\end{array}$ & Min & Max \\
\hline $\begin{array}{l}\text { Amount } \\
\text { raised }\end{array}$ & 277 & 3473 & 0 & 123,998 \\
\hline $\begin{array}{l}\text { Number of } \\
\text { donors }\end{array}$ & 1.83 & 11.36 & 0 & 421 \\
\hline $\begin{array}{l}\text { Number of } \\
\text { fundraisers }\end{array}$ & 0.04 & 1.25 & 0 & 97 \\
\hline $\begin{array}{l}\text { Number of } \\
\text { supporters }\end{array}$ & 3.24 & 12.40 & 0 & 501 \\
\hline $\begin{array}{l}\text { Degree } \\
\text { centrality - } \\
\text { donor }\end{array}$ & 0.316 & 1.00 & 0 & 7 \\
\hline $\begin{array}{l}\text { Eigenvector } \\
\text { centrality - } \\
\text { donor }\end{array}$ & 0.0006 & 0.029 & -0.168 & 0.452 \\
\hline $\begin{array}{l}\text { Degree } \\
\text { centrality - } \\
\text { supporter }\end{array}$ & 5.08 & 13.75 & 0 & 85 \\
\hline $\begin{array}{l}\text { Eigenvector } \\
\text { centrality - } \\
\text { supporter }\end{array}$ & 0.0024 & 0.013 & 0 & 0.112 \\
\hline
\end{tabular}

Table 2. Campaign pairs with shared donors or supporters

\begin{tabular}{|l|c|c|c|c|}
\hline $\begin{array}{c}\text { \# Shared } \\
\text { Donors or } \\
\text { Supporters }\end{array}$ & \multicolumn{2}{|c|}{$\begin{array}{c}\text { Campaign Pairs } \\
\text { with Shared } \\
\text { Donors }\end{array}$} & \multicolumn{2}{c|}{$\begin{array}{c}\text { Campaign Pairs } \\
\text { with Shared } \\
\text { Supporters }\end{array}$} \\
\cline { 2 - 5 } & Count & $\%$ & Count & $\%$ \\
\hline 1 & 27 & 0.000858 & 290 & 0.009214 \\
\hline 2 & 7 & 0.000222 & 5 & 0.000159 \\
\hline 3 & 1 & 0.000032 & 1 & 0.000032 \\
\hline 4 & 1 & 0.000032 & 2 & 0.000064 \\
\hline 5 & 0 & 0 & 1 & 0.000032 \\
\hline 6 & 1 & 0.000032 & 1 & 0.000032 \\
\hline 8 & 1 & 0.000032 & 0 & 0 \\
\hline
\end{tabular}

\subsection{Empirical Models}

Because we were only able to construct campaign networks for campaigns that had received donations, selection bias exists in our data analysis. To correct for this bias, we used the Heckman selection model [45]. In the first stage, we estimated a random effects Probit model to predict the probability that a campaign had received at least one donation by time $t$ :

$\operatorname{Pr}\left(\right.$ RecdDonation $\left._{i t}=1 \mid z_{i t}\right)=\Phi\left(z_{i t} \boldsymbol{\beta}_{\boldsymbol{1}}+\boldsymbol{D}_{t} \boldsymbol{\beta}_{\boldsymbol{2}}+v_{i}+\varepsilon_{i t}\right)$,

where RecdDonation ${ }_{i t}$ is a dummy variable with the value of 1 if Campaign $i$ had received at least one donation by time $t$ and 0 otherwise. $\Phi$ represents the standard cumulative normal distribution. $z$ it denotes a vector of exogenous campaign characteristics at time $t$ including the total number of images and videos the campaign initiator posted (NumImagesVideos ${ }_{i t}$ ), the natural logarithm of the number of words in the campaign's short description plus one $\left(\ln \left(\right.\right.$ NumWordsShortDesc $\left.\left._{i t}+1\right)\right)$, the natural logarithm of the number of words the campaign's detailed description plus one (In(NumWordsLongDesc $i t+1))$, the number of updates the campaign initiator had posted (NumUpdates ${ }_{i t}$ ), and the natural logarithm of the number of days remaining at time $t$ for campaign $i$ plus one $\left(\ln \left(\right.\right.$ NumDaysRem $\left.\left._{i t}+1\right)\right) . \boldsymbol{D}_{\boldsymbol{t}}$ is a vector of time dummies for the month of data collection. $v_{i}$ is the random effect for Campaign $i$ and follows a $\mathrm{N}\left(0, \sigma_{v}{ }^{2}\right)$ distribution. We used the random effects Probit model because of bias associated with fixed effects nonlinear models [46]. Based on the estimations of Equation 1, we calculated the inverse mills ratio and used it as an explanatory variable in the second stage analysis.

In the second stage, we estimated the amount of donation a campaign received during time $t$. A Hausman's test on the null hypothesis that random effects is the preferred model was rejected with a probability value less than 0.01 , hence we fitted a fixed effects model on the data. Similar to the approach used in Zhang and Liu [5], we estimated:

$\Delta y_{i t}=\alpha y_{i, t-1}+\boldsymbol{x}_{i, t-1} \boldsymbol{\beta}_{1}+Z_{i, t-1} \boldsymbol{\beta}_{2}+\boldsymbol{D}_{\boldsymbol{t}} \boldsymbol{\beta}_{3}+\mathrm{IMR}_{i, t-1}+\mu_{i}+\varepsilon_{i t}, \quad$ (2) where $\Delta y_{i t}$ is the natural logarithm of the amount of donation campaign $i$ received during time $t$ $\left(\ln \left(\right.\right.$ AmtReceived $\left.\left._{i t}+1\right)\right), \quad y_{i, t-1}$ represents the natural logarithm of the total amount of donation campaign $i$ received up until time t-1 plus one $\left(\ln \left(\right.\right.$ TotalAmtReceied $\left.\left._{i, t-1}+1\right)\right), \boldsymbol{x}_{i, t-1}$ is a vector of donorand supporter-based campaign network metrics for campaign $i$ during time $t-l, Z_{i, t-1}$ represents timevariant campaign characteristic variables that may affect campaign $i$ 's performance, $\boldsymbol{D}_{\boldsymbol{t}}$ is a vector of time dummies for the month of data collection, $\mathrm{IMR}_{i, t-1}$ is the inverse mills ratio for campaign $i$ at time $t-1$, and $\mu_{i}$ is the fixed effect of campaign $i$ and allowed us to 
capture the impacts of time-invariant campaign characteristics.

Table 3 summarizes the definitions of the variables used in both estimation models. Because of the low density of fundraiser-based campaign networks, there was high multicollinearity with the fixed effects when we added fundraiser-based network centralities into the models. As a result, we examined only donor- and supporter-based centralities in our data analysis. We further removed variables measuring the lengths of the short and long campaign descriptions and the number of campaign updates posted by the campaign initiator from the second-stage estimation because of multicollineary issues with the fixed effects.

Table 3. Variable definitions

\begin{tabular}{|c|c|}
\hline Variable & Definition \\
\hline RecdDonation $_{\text {it }}$ & $\begin{array}{l}\text { Dummy variable with the value of } 1 \text { if Campaign } i \text { had received at least one donation by } \\
\text { time } t ; 0 \text { otherwise. }\end{array}$ \\
\hline $\ln \left(\right.$ AmtReceived $\left._{i t}+1\right)$ & The natural logarithm of the amount of donation campaign $i$ received during time $t$. \\
\hline $\ln \left(\right.$ TotalAmtReceied $\left.{ }_{i, t-1}+1\right)$ & $\begin{array}{l}\text { The natural logarithm of the total amount of donation campaign } i \text { received up until time t-1 } \\
\text { plus one. }\end{array}$ \\
\hline NumImagesVideosit & The total number of images and videos the campaign initiator posted during time $t$. \\
\hline $\ln ($ NumWordsShortDescit +1$)$ & $\begin{array}{l}\text { The natural logarithm of the number of words in the campaign's short description during } \\
\text { time } t \text { plus one. }\end{array}$ \\
\hline $\ln ($ NumWordsLongDescit +1$)$ & $\begin{array}{l}\text { The natural logarithm of the number of words in the campaign's detailed description } \\
\text { during time } t \text { plus one. }\end{array}$ \\
\hline NumUpdates ${ }_{i t}$ & The number of updates the campaign initiator had posted up until time $t$. \\
\hline $\ln ($ NumDaysRemit +1$)$ & The natural logarithm of the number of days remaining at time $t$ for campaign $i$ plus one. \\
\hline $\ln ($ NumFacebookShares $i, t-1+1)$ & $\begin{array}{l}\text { The natural logarithm of the number of Facebook shares occurred during time } t \text { - } 1 \text { for } \\
\text { campaign } i \text { plus one. }\end{array}$ \\
\hline $\ln \left(\right.$ NumEmails $\left.s_{i, t-1+1}\right)$ & The natural logarithm of the number of emails sent during time $t-1$ for campaign $i$ plus one. \\
\hline $\ln ($ NumDonorsit,-1+1) & $\begin{array}{l}\text { The natural logarithm of the number of donors campaign } i \text { had accumulated up until time } t \text { - } \\
1 \text { plus one. }\end{array}$ \\
\hline $\ln ($ NumSupportersi,t-1+1) & $\begin{array}{l}\text { The natural logarithm of the number of supporters campaign } i \text { had accumulated up until } \\
\text { time } t-1 \text { plus one. }\end{array}$ \\
\hline$I M R_{i, t-1}$ & The inverse mills ratio for campaign $i$ at time $t-1$. \\
\hline DonorDegree $_{i, t-1}$ & The degree centrality of campaign $i$ in the donor-based campaign network at time $t-1$. \\
\hline DonorEigenvector $i, t-1$ & The Eigenvector centrality of campaign $i$ in the donor-based campaign network at time $t-1$. \\
\hline SupporterDegree $_{i, t-1}$ & The degree centrality of campaign $i$ in the supporter-based campaign network at time $t-1$. \\
\hline SupporterEigenvector ${ }_{i, t-1}$ & $\begin{array}{l}\text { The Eigenvector centrality of campaign } i \text { in the supporter-based campaign network at time } \\
t-1 \text {. }\end{array}$ \\
\hline
\end{tabular}

\section{Results}

\subsection{Random effects Probit selection model results}

The sample used for the first-stage random effects Probit selection model consisted of 6,781 monthly campaign observations on 2,509 campaigns. Table 4 summarizes the estimation results. All explanatory variables were significant at the 0.05 level or higher. The coefficients for NumImagesVideosit, $\ln$ (NumWordsShortDesc $\left.{ }_{i t}+1\right), \ln \left(\right.$ NumWordsLongDesc ${ }_{i t}$ +1 ), and NumUpdates $i t$ were all positive, indicating that posting more pictures and videos, giving lengthier brief and detailed descriptions, and frequently updating the campaign page increased the likelihood of a campaign receiving at least one donation. The coefficient for In(NumDaysRem $\left.{ }_{i t}+1\right)$ was negative, suggesting that campaigns that had more days remaining were associated with a lower probability of receiving at least one donation.

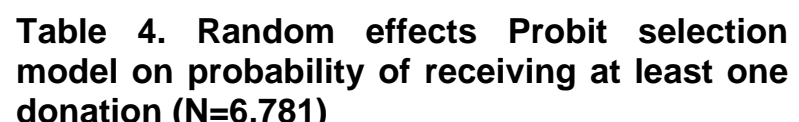

\begin{tabular}{|l|c|}
\hline Variable & $\begin{array}{c}\text { Coefficient } \\
\text { (Std. Dev.) }\end{array}$ \\
\hline NumImagesVideos $i t$ & $1.373 * * *$ \\
& $(0.099)$ \\
\hline In(NumWordsShortDesc $i t+1)$ & $1.274 * *$ \\
& $(0.351)$ \\
\hline ln(NumWordsLongDescit +1$)$ & $1.961 * * *$ \\
& $(0.053)$ \\
\hline NumUpdates $i t$ & $3.831 * * *$ \\
& $(0.294)$ \\
\hline ln(NumDaysRem $i t+1)$ & $-0.129 * *$ \\
& $(0.056)$ \\
\hline Time Dummies & Included \\
\hline Constant & $-21.206 * * *$ \\
& $(1.299)$ \\
\hline Wald $\chi^{2}$ & $1700.36 * * *$ \\
\hline$* p<0.1 ; * *<0.05 ; * * *<0.01$. & \\
\hline
\end{tabular}




\subsection{Fixed effects model results}

The sample used for the second-stage fixed effects estimation included 291 monthly campaign observations on 162 campaigns. The sample size reduced significantly from the first-stage analysis because of the selection bias and the use of lagged independent variables. The inverse mills ratio (IMR) was used to control for the selection bias. Pair-wise correlation analysis of the independent variables reveals that all independent variables had pair-wise correlations between -0.6 and 0.6 , with the exception of $\ln \left(\right.$ AmtReceived $\left._{i t}+1\right)$ and $\ln \left(\right.$ NumDonors $\left._{i, t-1}+1\right)$ having a correlation of 0.87 and SupporterDegree $i, t-1$ and SupporterEigenvector ${ }_{i, t-1}$ having a correlation of 0.72. In subsequent analyses, we added them into our empirical models separately. To control for heteroskedasticity and autocorrelation, we used the robust standard errors. Table 5 summarizes the results of our second-stage fixed effects estimation of three sets of models. Base model $2 \mathrm{~A}$ includes campaign characteristics and the IMR. Models 2B and 2C include additional independent variables that capture Fundly users' social media sharing, donation, and supporting behaviors. Models 2D through $2 \mathrm{G}$ include additional campaign network centrality variables. The coefficient for NumImagesVideosit was positive and significant in all seven models, indicating that posting more pictures and videos contributed positively to campaign success. The coefficient for $\ln$ (TotalAmtReceied $\left._{i, t-1}+1\right)$ was negative and significant in Model 2A and the coefficients for $\ln \left(\right.$ NumSupporters $\left._{i, t-1}+1\right)$ were negative and significant in Models 2B through 2G, corroborating the observed substitution effects in the donation to public goods [4]. When we took into consideration of the network centralities in Models 2D through 2G, DonorDegree $_{i, t-1}$ had negative and significant coefficient estimates, thus supporting H1a. SupporterDegree $_{i, t-1}$ had positive and significant coefficient estimates in Models 2D and 2E, supporting H2a. The coefficient estimates for DonorEigenvector $r_{i,-}$ 1 and SupporterEigenvector $r_{i, t-1}$ were non-significant, thus $\mathrm{H} 1 \mathrm{~b}$ and $\mathrm{H} 2 \mathrm{~b}$ were not supported. The adjusted $\mathrm{R}^{2}$ 's for Models $2 \mathrm{D}$ through $2 \mathrm{G}$ were higher than those of Models 2A through 2C, thus the network centralities improved the predictability of campaign success.

Table 5. Fixed effects model on donation amount ( $\mathrm{N}=291)$

\begin{tabular}{|c|c|c|c|c|c|c|c|}
\hline \multirow[t]{2}{*}{ Variable } & \multirow{2}{*}{$\begin{array}{c}\text { Base } \\
\text { Model }\end{array}$} & \multicolumn{2}{|c|}{$\begin{array}{l}\text { Models with social } \\
\text { media sharing, donor, } \\
\text { and supporter variables }\end{array}$} & \multicolumn{4}{|c|}{ Models with campaign network centralities } \\
\hline & & Model 2B & Model 2C & Model 2D & Model 2E & Model 2F & Model 2G \\
\hline $\begin{array}{l}\ln (\text { TotalAmtReceied } \\
, t-I+1)\end{array}$ & $\begin{array}{l}-1.919 * \\
(1.023)\end{array}$ & $\begin{array}{l}-1.457 \\
(1.187)\end{array}$ & & $\begin{array}{l}-1.493 \\
(1.104)\end{array}$ & & $\begin{array}{l}-1.466 \\
(1.141)\end{array}$ & \\
\hline NumImagesVideosit & $\begin{array}{l}0.762 * * * \\
(0.168)\end{array}$ & $\begin{array}{l}1.617 * * * \\
(0.441)\end{array}$ & $\begin{array}{l}1.723 * * * \\
(0.543)\end{array}$ & $\begin{array}{l}1.823 * * * \\
(0.488)\end{array}$ & $\begin{array}{l}1.944 * * * \\
(0.569)\end{array}$ & $\begin{array}{l}1.382 * * * \\
(0.380)\end{array}$ & $\begin{array}{l}1.509 * * * \\
(0.492)\end{array}$ \\
\hline $\begin{array}{l}\ln (\text { NumDaysRem } \\
\text { it }\end{array}$ & $\begin{array}{c}0.103 \\
(0.170) \\
\end{array}$ & $\begin{array}{c}0.145 \\
(0.178) \\
\end{array}$ & $\begin{array}{c}0.177 \\
(0.191) \\
\end{array}$ & $\begin{array}{c}0.040 \\
(0.151) \\
\end{array}$ & $\begin{array}{c}0.082 \\
(0.164) \\
\end{array}$ & $\begin{array}{c}0.086 \\
(0.159) \\
\end{array}$ & $\begin{array}{c}0.123 \\
(0.171) \\
\end{array}$ \\
\hline $\begin{array}{l}\ln (\text { NumFacebookSh } \\
\text { aresi,t-1+1) }\end{array}$ & & $\begin{array}{l}-0.171 \\
(0.203)\end{array}$ & $\begin{array}{l}-0.231 \\
(0.156)\end{array}$ & $\begin{array}{l}-0.108 \\
(0.178)\end{array}$ & $\begin{array}{l}-0.180 \\
(0.135)\end{array}$ & $\begin{array}{l}-0.089 \\
(0.177)\end{array}$ & $\begin{array}{l}-0.157 \\
(0.130)\end{array}$ \\
\hline $\ln \left(\right.$ NumEmails $\left._{i, t-1}+1\right)$ & & $\begin{array}{c}0.122 \\
(0.472) \\
\end{array}$ & $\begin{array}{c}0.018 \\
(0.495) \\
\end{array}$ & $\begin{array}{c}0.328 \\
(0.454) \\
\end{array}$ & $\begin{array}{c}0.224 \\
(0.467) \\
\end{array}$ & $\begin{array}{c}0.198 \\
(0.455) \\
\end{array}$ & $\begin{array}{c}0.097 \\
(0.465) \\
\end{array}$ \\
\hline $\begin{array}{l}\ln (\text { NumDonors } \\
1, t-1) \\
1+1)\end{array}$ & & & $\begin{array}{l}-2.029 \\
(1.792) \\
\end{array}$ & & $\begin{array}{l}-1.967 \\
(1.684) \\
\end{array}$ & & $\begin{array}{l}-1.975 \\
(1.710) \\
\end{array}$ \\
\hline $\begin{array}{l}\ln (\text { NumSupporters } i, t- \\
+1)\end{array}$ & & $\begin{array}{l}-1.746 * * \\
(0.780) \\
\end{array}$ & $\begin{array}{c}-1.896^{*} \\
1.004) \\
\end{array}$ & $\begin{array}{l}-1.387 * * \\
(0.697)\end{array}$ & $\begin{array}{l}-1.585^{*} \\
(0.935) \\
\end{array}$ & $\begin{array}{l}-1.475^{* *} \\
(0.714)\end{array}$ & $\begin{array}{l}-1.652^{*} \\
(0.941)\end{array}$ \\
\hline$I M R_{i, t-1}$ & $\begin{array}{c}0.604 \\
(0.470) \\
\end{array}$ & $\begin{array}{c}0.616 \\
(0.476) \\
\end{array}$ & $\begin{array}{c}0.631 \\
(0.476) \\
\end{array}$ & $\begin{array}{c}0.701 \\
(0.471) \\
\end{array}$ & $\begin{array}{l}0.710^{*} \\
(0.425) \\
\end{array}$ & $\begin{array}{c}0.615 \\
(0.474) \\
\end{array}$ & $\begin{array}{c}0.629 \\
(0.429) \\
\end{array}$ \\
\hline DonorDegree $_{i, t-1}$ & & & & $\begin{array}{l}-1.867 * * * \\
(0.154) \\
\end{array}$ & $\begin{array}{l}-1.844 * * * \\
(0.160)\end{array}$ & $\begin{array}{l}-1.831 * * * \\
(0.156)\end{array}$ & $\begin{array}{l}-1.810^{* * * *} \\
(0.162)\end{array}$ \\
\hline $\begin{array}{l}\text { DonorEigenvector }{ }_{i, t-} \\
1\end{array}$ & & & & $\begin{array}{c}3.063 \\
(3.392)\end{array}$ & $\begin{array}{c}3.156 \\
(3.519) \\
\end{array}$ & $\begin{array}{c}3.093 \\
(3.460)\end{array}$ & $\begin{array}{c}2.909 \\
(3.507)\end{array}$ \\
\hline SupporterDegree $_{i, t-1}$ & & & & $\begin{array}{r}0.257^{*} \\
(0.141) \\
\end{array}$ & $\begin{array}{r}0.248^{*} \\
(0.140) \\
\end{array}$ & & \\
\hline $\begin{array}{l}\text { SupporterEigenvect } \\
\text { or } r_{i, t-1}\end{array}$ & & & & & & $\begin{array}{l}-471.305 \\
(339.780) \\
\end{array}$ & $\begin{array}{l}-447.611 \\
(336.042) \\
\end{array}$ \\
\hline Constant & $\begin{array}{c}5.533 \\
(7.589)\end{array}$ & $\begin{array}{c}1.723 \\
(8.346) \\
\end{array}$ & $\begin{array}{l}-3.235 \\
(5.026)\end{array}$ & $\begin{array}{l}-0.104 \\
(8.033)\end{array}$ & $\begin{array}{l}-5.315 \\
(5.114)\end{array}$ & $\begin{array}{c}4.093 \\
(8.107)\end{array}$ & $\begin{array}{l}-1.110 \\
(4.873)\end{array}$ \\
\hline Time dummies & Included & Included & Included & Included & Included & Included & Included \\
\hline Adjusted $\mathrm{R}^{2}$ & 0.744 & 0.744 & 0.740 & 0.782 & 0.776 & 0.772 & 0.767 \\
\hline
\end{tabular}

$* p<0.1 ; * * p<0.05 ; * * * p<0.01$. 


\subsection{Robustness checks}

We checked for multicollinearity for all models using variance inflation factors (VIFs) for each variable. All VIFs were lower than five, indicating that multicollinearity was not an issue in our data analysis.

The amount of time a campaign has been listed on Fundly may influence the amount of donation it receives due to more exposure by a campaign that has been ongoing for a long time. Because Fundly does not list the starting time of a campaign, we used a subset of our sample with campaigns launched during our data collection to examine the effects of the length of a campaign in months on donation received. Our results indicate campaign length was not significant in either the stage one selection model or Model 2A. Hence, campaign length does not affect campaign success.

\section{Discussion}

Our research on the impacts of donor- and supporter-based campaign networks on crowdfunding campaign success has the following major findings.

First, our research contributes to the crowdfunding literature by revealing the importance of informal internal social network on crowdfunding success. The uniqueness of our research is that we examined campaign networks formed as a result of internal social capital and investigated the effects of campaign network on crowdfunding success. Specifically, we inspected ties of two different strengths: strong ties formed due to donation relationships and weak ties formed due to supporting relationships. Based on these two types of ties, we constructed different campaign networks. Such campaign networks are informative for two different reasons. First, they allowed us to go beyond simple social network measures such as the number of friends or donors a borrower has. Two campaigns will only be connected when they share the same donor or supporter. Hence, the importance of occasional or armature donors or supporters who donated to or supported only one campaign is downplayed in our research. Second, the donor- and supporter-based networks allowed us to examine how the strength of the ties between two campaigns affected their success differently. While donor-based (strong ties) campaign networks may impose competition among neighboring nodes, supporter-based (weak ties) campaign networks provide complementary connections that facilitate campaign success.

Second, our research contributes to the SNA literature by applying it to the crowdfunding context. Our results show that degree centrality is a more informative predictor of campaign success than many campaign characteristics, social media sharing behavior, or simple social network measures such as the number of donors. The degree centrality of a campaign in the donor-based campaign network is negatively related to the amount of donation it receives in the next period. This may be due to two reasons. First, donor-based ties (strong ties) may connect campaigns with high homophily possibly due to similar causes or geographic locations [37, 38]. These similar campaigns compete against each other for donations from the Fundly community. As a result, when a campaign has a high degree in the donor-based campaign network, it faces more fierce competition coming from many other similar campaigns, thus leading to a smaller donation it receives in the future. Second, on Fundly, community members can go from one campaign to another through shared donors. When a campaign is connected to many other campaigns through shared donors, it has many paths that may funnel in visitors to or out of the campaign page. The negative relationship indicates that the net effect may be the outflow of visitors from a campaign page. The degree centrality of a campaign in the supporter-based campaign network is positively related to the amount of donation it receives in the next period. According to SNT, weak ties usually connect nodes that are more different and thus provide bridges to other components that facilitate the inflow of different resources such as information and social capital [22]. In the case of the supporter-based campaign networks, having a high degree means a campaign is connected to many other campaigns that are different from itself. This linkage creates a path that funnels in visitors from other campaign pages. Because these visitors usually browse and donate to campaigns different from the focal one, having increased exposure from a new audience leads to more donation the campaign receives in the next period. Even though users can go from one campaign to another through shared donors and supporters, the fact that the eigenvector centralities are non-significant but degree centralities are indicates that only a campaign's immediately connections matter. That is, Fundly users only go from one campaign to its immediate neighboring campaigns through shared donors and supporters, but do not further propagate the campaign networks to other connected campaigns.

\section{Practical Implications}

The current research provides the following insights to crowdfunding service providers. First, our results highlight the influence of both strong and weak ties on crowdfunding campaign success. Even though there are many crowdfunding platforms, Fundly is the only one that we discovered as allowing community members to show their support of a campaign and 
provides a path of going from one campaign to another through shared donors and supporters. Our results indicate that crowdfunding providers should consider adding the supporting feature and providing the connections between campaigns through shared supporters so as to facilitate the flow of members from one campaign to another. Second, the current research reveals the importance of being connected to other different campaigns on crowdfunding platforms. Even though most crowdfunding websites highlight and show in prominent locations on a campaign page the number of donors and amount received to date, surprisingly our results show that this information is not as important as connections to other more different campaigns. As a result, crowdfunding platforms should consider adding links from one campaign page to other campaigns in different geographic locations or for different causes. This way, traffic may be redirected and members can donate to other campaigns.

\section{Conclusion}

The current research examines how campaign network structures affect the success of crowdfunding projects. Based on panel data collected from Fundly, a donation-based crowdfunding platform, our empirical analyses show that a campaign's degree centralities in both donor-based (strong ties) and supporter-based (weak ties) campaign networks are important predictors of campaign success. Contrary to popular conception, social media sharing behaviors and the number of donors are not important predictors of future donations a campaign receives.

Our research has the following limitations. First, our sample size is small due to the limited months of data we have. As we continue to collect monthly campaign data from Fundly, we expect to increase our sample size quickly and will be able to analyze our data using dynamic models and system generalized method of moments (GMM) estimator [47, 48], which require more lag periods. Second, when constructing the donor- and supporter-based networks, we did not take into consideration the tie weights of the campaign networks. Future research can examine these networks by incorporating the weights of the ties. This approach may further allow researchers to combine the donorand supporter-based campaign networks that we use in the current research into one network. Third, we used the amount of donation a campaign receives as an indicator of campaign success. Future research can use other measures such as reaching the fundraising goal. Fourth, athough our research reveals the importance of network structures on campaign success, we cannot infer causality. Future research can examine if other factors such as the importance, popularity, or size of the campaign lead to shared donors or supporters.

\section{References}

[1] R. E. Wheat, Y. Wang, J. E. Byrnes, and J. Ranganathan, "Raising money for scientific research through crowdfunding," Trends in Ecology \& Evolution, vol. 28, no. 2, pp. 71-72, 2// 2013.

[2] C. Barnett. (2015, May 25). Trends Show Crowdfunding To Surpass VC in 2016. Available: http://www.forbes.com/sites/chancebarnett/2015/06/09/trends -show-crowdfunding-to-surpass-vc-in-2016/\#209b44b5444b [3] Infiniti Research Ltd., "Global Crowdfunding Market 2016-2020," Dublin, Ireland2016, Available: http://www.reportlinker.com/p03588291-summary/GlobalCrowdfunding-Market.html.

[4] G. Burtch, A. Ghose, and S. Wattal, "An Empirical Examination of the Antecedents and Consequences of Contribution Patterns in Crowd-Funded Markets," Information Systems Research, Article vol. 24, no. 3, pp. 499-519, 2013.

[5] J. Zhang and P. Liu, "Rational Herding in Microloan Markets," Management Science, Article vol. 58, no. 5, pp. 892-912, 2012.

[6] E. Mollick, "The dynamics of crowdfunding: An exploratory study," Journal of Business Venturing, Article vol. 29, no. 1, pp. 1-16, 2014.

[7] M. G. Colombo, C. Franzoni, and C. Rossi-Lamastra, "Internal Social Capital and the Attraction of Early Contributions in Crowdfunding," Entrepreneurship: Theory \& Practice, Article vol. 39, no. 1, pp. 75-100, 2015.

[8] T. Hildebrand, M. Puri, and J. Rocholl, "Adverse Incentives in Crowdfunding," Management Science, 2016.

[9] D. Liu, D. J. Brass, Y. Lu, and D. Chen, "Friendships in Online Peer-to_peer Lending: Pipes, Prisms, and Relational Herding," MIS Quarterly, Article vol. 39, no. 3, pp. 729-742, 2015.

[10] J. Scott, Social Network Analysis, Third Ed ed. Los Angeles: Sage, 2012.

[11] M. Meyskens and L. Bird, "Crowdfunding and Value Creation," Entrepreneurship Research Journal, Article vol. 5, no. 2, pp. 155-166, 2015.

[12] M. Lin, N. R. Prabhala, and S. Viswanathan, "Judging Borrowers by the Company They Keep: Friendship Networks and Information Asymmetry in Online Peer-to-Peer Lending," Management Science, Article vol. 59, no. 1, pp. 17-35, 2013.

[13] M. Granovetter, "The strength of weak ties," American Journal of Sociology, vol. 78, no. 6, pp. 1360-1380, 1973.

[14] B. Wellman, "Computer networks as social networks," Science, vol. 293, no. 5537, pp. 2031-2034, 2001.

[15] L. Garton, C. Haythornthwaite, and B. Wellman, "Studying online social networks," Journal of Computer Mediated Communication, vol. 3, no. 1, pp. 0-0, 1997.

[16] C. Haythornthwaite, "Online Personal Networks Size, Composition and Media Use among Distance Learners," New Media \& Society, vol. 2, no. 2, pp. 195-226, 2000.

[17] D. Constant, L. Sproull, and S. Kiesler, "The kindness of strangers: The usefulness of electronic weak ties for technical 
advice," Organization science, vol. 7, no. 2, pp. 119-135, 1996.

[18] T. H. Feeley and G. A. Barnett, "Predicting employee turnover from communication networks," Human Communication Research, vol. 23, no. 3, pp. 370-387, 1997.

[19] G. DeSanctis and M. S. Poole, "Capturing the complexity in advanced technology use: Adaptive structuration theory," Organization science, vol. 5, no. 2, pp. 121-147, 1994.

[20] C. Haythornthwaite, M. M. Kazmer, J. Robins, and S. Shoemaker, "Community development among distance learners: Temporal and technological dimensions," Journal of Computer - Mediated Communication, vol. 6, no. 1, pp. 0$0,2000$.

[21] H. Noel, "Towards a Networks Theory of Political Parties," in American Political Parties: Past, Present and Future Conference, Charlottesville, VA, 2012.

[22] D. Easley and J. Kleinberg, Networks, Crowds, and Markets: Reasoning about a Highly Connected World. New York, NY: Cambridge University Press, 2010.

[23] M. T. Hansen, "The Search-Transfer Problem: The Role of Weak Ties in Sharing Knowledge across Organization Subunits," Administrative Science Quarterly, Article vol. 44, no. 1, pp. 82-111, 1999.

[24] D. J. Brass, "Being in the Right Place: A Structural Analysis of Individual Influence in an Organization," Administrative Science Quarterly, Article vol. 29, no. 4, pp. 518-539, 1984.

[25] R. E. Nelson, "The Strength of Strong Ties: Social Networks and Intergroup Conflict in Organizations," Academy of Management Journal, Article vol. 32, no. 2, pp. 377-401, 1989.

[26] J. E. Perry-Smith, "Social Network Ties Beyond Nonredundancy: An Experimental Investigation of the Effect of Knowledge Content and Tie Strength on Creativity," Journal of Applied Psychology, Article vol. 99, no. 5, pp. 831-846, 2014.

[27] Y. Zenou, "A Dynamic Model of Weak and Strong Ties in the Labor Market," Journal of Labor Economics, Article vol. 33, no. 4, pp. 891-932, 2015.

[28] H. Ahn and J.-H. Park, "The structural effects of sharing function on Twitter networks: Focusing on the retweet function," Journal of Information Science, Article vol. 41, no. 3, pp. 354-365, 2015.

[29] S. Zhan, R. Huaxia, and A. B. Whinston, "Content Sharing in a Social Broadcasting Environment: Evidence from Twitter," MIS Quarterly, Article vol. 38, no. 1, pp. 123A6, 2014.

[30] L. C. Freeman, D. Roeder, and R. R. Mulholland, "Centrality in social networks: II. Experimental results," Social networks, vol. 2, no. 2, pp. 119-141, 1979.

[31] M. E. J. Newman, "A measure of betweenness centrality based on random walks," Social Networks, vol. 27, no. 1, pp. 39-54, 2005.

[32] M. K. Ahuja, D. F. Galletta, and K. M. Carley, "Individual Centrality and Performance in Virtual R\&D Groups: An Empirical Study," Management Science, Article vol. 49, no. 1, pp. 21-38, 2003.

[33] A. Susarla, O. Jeong-Ha, and T. Yong, "Social Networks and the Diffusion of User-Generated Content: Evidence from
YouTube," Information Systems Research, Article vol. 23, no. 1, pp. 23-41, 2012.

[34] A. Mehra, A. L. Dixon, D. J. Brass, and B. Robertson, "The Social Network Ties of Group Leaders: Implications for Group Performance and Leader Reputation," Organization Science, Article vol. 17, no. 1, pp. 64-79, 2006.

[35] A. Abbasi, J. Altmann, and L. Hossain, "Identifying the effects of co-authorship networks on the performance of scholars: A correlation and regression analysis of performance measures and social network analysis measures," Journal of Informetrics, vol. 5, no. 4, pp. 594607, 2011.

[36] W. Bolander, C. B. Satornino, D. E. Hughes, and G. R. Ferris, "Social Networks Within Sales Organizations: Their Development and Importance for Salesperson Performance," Journal of Marketing, vol. 79, no. 6, pp. 1-16, 2015.

[37] G. Burtch, A. Ghose, and S. Wattal, "Cultural Differences and Geography as Determinants of Online Prosocial Lending," MIS Quarterly, Article vol. 38, no. 3, pp. 773-794, 2014.

[38] M. Lin and S. Viswanathan, "Home Bias in Online Investments: An Empirical Study of an Online Crowdfunding Market," Management Science, vol. 62, no. 5, pp. 1393-1414, 2016/05/01 2015.

[39] A. Agrawal, C. Catalini, and A. Goldfarb, "Crowdfunding: Geography, Social Networks, and the Timing of Investment Decisions," Journal of Economics \& Management Strategy, Article vol. 24, no. 2, pp. 253-274, Summer2015 2015.

[40] J. Galak, D. Small, and A. T. Stephen, "Microfinance Decision Making: A Field Study of Prosocial Lending," Journal of Marketing Research (JMR), Article vol. 48, pp. S130-S137, 2011.

[41] J. Meer, "Effects of the price of charitable giving: Evidence from an online crowdfunding platform," Journal of Economic Behavior \& Organization, Article vol. 103, pp. 113-124, 2014.

[42] L. Corazzini, C. Cotton, and P. Valbonesi, "Donor coordination in project funding: Evidence from a threshold public goods experiment," Journal of Public Economics, Article vol. 128, pp. 16-29, 2015.

[43] N. E. Friedkin, "Information flow through strong and weak ties in intraorganizational social networks," Social Networks, vol. 3, no. 4, pp. 273-285, 1982.

[44] S. P. Borgatti, M. G. Everett, and L. C. Freeman, UCINET 6 for Windows: Software for Social Network Analysis. Harvard, MA: Analytic Technologies, 2002.

[45] J. J. Heckman, "Sample Selection Bias as a Specification Error," Econometrica, Article vol. 47, no. 1, pp. 153-161, 1979.

[46] W. Greene, "The behaviour of the maximum likelihood estimator of limited dependent variable models in the presence of fixed effects," Econometrics Journal, Article vol. 7, no. 1, pp. 98-119, 2004.

[47] M. Arellano and O. Bover, "Another look at the instrumental variable estimation of error-components models," Journal of Econometrics, Article vol. 68, no. 1, pp. 29-51, 1995.

[48] R. Blundell and S. Bond, "Initial conditions and moment restrictions in dynamic panel data models," Journal of Econometrics, Article vol. 87, no. 1, pp. 115-143, 1998. 